gently pulled down and pressed back, will succeed in some cases; but it often will fail entirely. The air may, in truth, not be admitted at all into the windpipe; and, instead of the lungs, the gullet and stomach may be distended. It is a mistake to suppose that in all cases of asphyxia-or evell when actual death has taken place-that the rima glottidis is quite pervio (5. $^{\text {s. }}$

In not a few instances has the epiglottis been found on dissection to be closely applied to the opening of the larynx, so that all attempts to inflate the lungs, by blowing air from the mouth or nostrils, must be entirely ineffectual. This state has been observed to be, on the whole, more frequently the case in that kind of asphyxia induced by the inbalation of carbonic acid, than in any other. It may be well therefore, whenever wh have reason to suspect that the insufllated air does not readily enter the air-tubes, that we either introduce an elastic tube, a catheter or such-jike instrument, into the larynx from the mouth or nares, or proceed at once to the operation of laryngotomy. The mere division of the integuments and maki $0_{0}^{\circ}$ an opening into the larynx are attended with but trifling danger; and the time that may be thus saved and the direct and easy introduction of the air into the lungs, thus performed, are most important advantages. It is mot than probable that, if the operation were more frequently performed at once. and no time were lost in making attempts to inflate the lungs in the or dinary manner, not a few lives might be saved. When we have every neces sary and convenient instruments, such as tubes, bellows, \&c. at hand, the operation may be generally dispensed with; but summoned unexpectedly, ${ }^{35}$ the surgeon usually is to a case of suspended animation, without the benefit either of assistants or even of the appropriate instruments, we should advise him to open the larynx at the thyro-cricoid space, and, either directly with his mouth or with the aid of a short tube inserted into the wound, keep up a continued and regular insuftlation of the chest for a considerable leng of time, until natural respiration is re-established.

\title{
COMPARATIVE ANATOMY.
}

\section{NERVOUS SYSTEM OF THE AMPHIBIA.}

I. Illustrations of the Comparative Anatomy of t th $^{b}$ Nervous System. By Joseph Swan. Part III. Price $\eta^{\text {s. }}$ Quarto, pp. 21. Plates VI. Longman's, London, 1837. II. Outhines of Comparative Anatomy. By Robert $\boldsymbol{E}$. Grant, M.D. \&c. \&c. \&c. Part Third. London. Bailliere, Part Fourth, 1837. Price Four Shillings each Part.

Mr. Swan is, as all our readers, nay as all the profession know, a ver? zealous cultivator of anatomy. With unwearied assiduity, he ascertains th facts on which hypotheses are grounded and by which they must finally tried. To his pages we may always turn with the certainty of finding faith representations of nature, and the library of the philosophical physician ${ }^{\text {of }}$ surgeon is defective unless it contains them. 

The first Plate of the present Part exhibits the distribution of the olfactory
nerve, of the fifth nerve, of the splanchnic and visceral branches of the
sympathetiction

sympathetic nerve of the turtle.

The second plate represents the sympathetic nerve of the turtle.

The third plate gives a general view of the nerves of the turtle.

the fourth plate represents the brain of the turtle-the nerves of the frog

same- brain and posterior or superior stirface of the spinal marrow of the

The the brain of the boa-constrictor-the spinal cord of the same.

strictor.

The

The sixth plate displays the sympathetic nerve of the snake.

amphib part concludes with some observations on the nervous system of the that thes, which we shall introduce to our readers. We should premise snake observations have been entirely derived from dissections of the does well frog, and two species of turtle, a circumstance which Mr. Swan

The lo mention in a distinct manner.

ternally brain of amphibia, says Mr. Swan, differs from that of fishes exthe anterior the size and shape of several parts. In the larger size of in this lobes, in which there is a capacious ventricle, a prominence plexus that may be compared with the striated body and a choroid $\mathrm{l}_{\mathrm{ami}} \mathrm{i}$, in not having any mammillary eminences. In having small thabut connected together in the turtle by a very tenacious commissure, but not placed as in mammalia with respect to the lateral ventricles, remarkabl these and out of the cavities, and their situation is even mure missures in the frog. In having posterior as well as anterior comoptic lob the anterior alone existing in some fishes. The ventricle in the extendine is very similar; but in the floor of this, the logiturlinal bands in the towards the calamus scriptorius are more prominent. It differs having very dense membrane covering it, especially in the turtle, in not memb su much space in the skull, and not being placed in a fine reticulated one.

and round cerebellum of the turtle differs from that of fishes in its smoothness

in the skatness, in not having lobes or an appearance of convolutions, as

ventricle. In the

not the snake, the brain is nearly the same as in the turtle; and there is In the difference in the frog, except that the thalami appear externally. parison snake and frog the cerebellum is so small, as hardly to bear a comDr. With that of the turtle or fishes.

arva Grant remarks that; - in the perennibranchiate ampbibia, and in the gata, and of those which lose the gills, the spinal cord, the medulla oblonproportions the cerebral parts contained within the cranium present the same ters in and general conditions which we observe as permanent characin most of the osseous fishes; but the cerebellum is generally smaller fishes, the and reptiles than in all the other vertebrata. As in the lower small the spinal chord in these inferior forms of amphibia is prolonged, With and tapering, through the greater part of the coccygeal vertebra, arms and distinct enlargements where the nerves usually come off to the and to the legs. The medulla oblongata is yet broad and lobed, the 
cerebellum in form of a very small median transverse lobe without hemispheres, the optic lobes large, cineritious, smooth without, hollow within, and quite exposed, and the cerebral hemispheres, extended longitudinally, smooth and cineritious externally, without internal ventricles, and snialler" than the optic lobes. The metamorphusis of the caducibranchiate species changes the condition of their nervous system from that of the lower fishes to nearly that of the reptiles above them; and these changes are effected ${ }^{50}$ rapidly that we can perceive a marked advancement in the development ${ }^{0}$ the nervous system of the tadpole produced in one day.

The long narrow cerebral hemispheres of adult frogs, proceeds Dr. Grant, taper to the olfactory nerves which commence with cineritious tubercles, and the optic nerves are observed distinctly to cross each other before the optic tubercles. The changes effected in the nervous system by the meta morphosis of the higher amphibia closely resemble those produced by dere lopment in the human embryo.

In the class of reptiles, we still quote Dr. Grant, the small cavity of the cranium nearly corresponds with the dimensions of the enclosed brain, as in some fishes, and the superficial cineritious substance still predominates $0^{\text {ver }}$ the internal white fibrous matter, though to a less extent than in fishes and amphibia. The cerebellum is remarkable for its proportionate smallness ${ }^{\text {in }}$ this class, and the cerebral bemispheres, containing each a distinct ventricle, now always exceed the optic lobes. The spinal chord of serpents, from theis want of arms and legs, is still destitute of enlargements, as in the apodal fishes, but the medulla oblongata is of considerable size, and the four ventricle, still uncovered by the small cerebellum, descends into the spind chord. From the smallness of the brain and cranial cavity in the centre the head of reptiles, the relative size of these parts does not influence the of the whole head at different periods of life, and the head preserves same proportions to the rest of the body through life also in amphibia an fishes. From the still imperfect development of the cerebral parts in th class, the vital functions of reptiles are less immediately dependent on the than in hot-blooded animals, and they longer survive their mutilation.

We now return to Mr. Swan. The observations we are about to int $\mathrm{r}^{\circ}$ duce appear to us to be important, particularly at the present moment, whet the excito-motory bypothesis is attracting general attention.

"The brain of amphibia, compared with that of fishes, is rather more com" plicated, but still has very littlo development of parts ministering to the genel functions of the body; the principal portions are larger $r$ or smaller, accor r $^{\text {dite }}$ to the required extent of the senses and the power of intellect. In both the classes the oblong medulla bears a greater proportion to the size of the than in the higher, and seems to be equally connected with the animal function the and the lobes of the brain, as in them, to be superadded. The large size of ble spinal marrow, as compared with that of the brain, is also very remarka When, therefore, the vast intricacy and number of the organs of the body both these classes is considered, and that they are nearly as great as in the is higher classes, and when it is observed how small the size of the brain is proportion to the nerves, it must be concluded that both the oblong and spis medulla have peculiar and important functions; as the nerves bear no prop pla tion to the size of the brain, but only to that of the oblong and spinal med it must also be concluded that their power is principally derived from theit parts. Appropriate functions are, however, performed by the nerves and 
Sanglia, and it may be presumed that some power is inherent in them, for there mals.

The power of the nervous system is, in many respects, increased or diminished according to the quantity of nervous matter forming the centres, and the supply by quality of the circulating fluids. When the blood is less perfectly changed howe restion, the brain is less, as in fishes and amphibia; the spinal marrow, the sup, is not less, but is proportionate to the requisite quantity of nerves for of fluids, of the body, as in birds and mammalia. The more extensive change tion of as in these higher classes, is not therefore necessary for the preservaoxygen the nervous matter; but a greater bulk of brain under this imperfect tent with of the blood, as in fishes and amphibia, is not generally consis-

even with the free and healthy functions of the various organs of the body, and

row with the maintenance of life. The structure of the brain and spinal mar-

malia f fishes and amphibia is somewhat different from that of birds and mam-

it is ; but they can display great muscular power in the same manner, although

When the whether they can maintain it for the same time.

tures the circulation is more languid, the animals exposed to low tempera-

that the motions of the tail not very great in individual parts, it appears

equina continuation of the spinal marrow is preferred to the usual cauda

thus of mammalia; and it is very probable that the power of the nerves is

stances, easily intercepted, and the functions of the parts, under all circum-

ticularly are more certainly preserved. But even in the higher classes, and par-

it arly in birds, when the spinal marrow can be conveniently accommodated,

nerves with greater security allow of the distribution of the numerous small es issuing from it." $7 \mathrm{i}$.

Of course it would be unphilosophical to look upon the condition of the

nervous system or on that of the vasculo-respiratory as respectively cause or

holds the one of the other. The entire class to which the animal belongs

another.

one ano The subordinate systems of which it is composed harmonize with

tive power, and are all regulated by some general laws and occult forma-

loped ther. If here and there some particular organ is more highly deve.

its perfan in higher classes, it is evidently for a special purpose, and even Derfection is confined within definite limits.

and r. Grant remarks that in the saurian and chelonian reptiles the posterior

the middle enlargements are obvious on the spinal chord at the origins of craniumes of the extremities. The wide medulla oblongata within the ciculi is marked longitudinally by the limits of its three component fasare m each side, and the decussating bands of its corpora pyramidalia portion distinct than in fishes. The nerves of the body bear a large protion to the size of the cerebral centres, and correspond in their distribuplexuses those of the higher air-breathing classes. The great ganglia and runks, of the sympathetics now more closely accompany the arterial articul, as we see to become more exclusively their distribution from the cranial and the molluscous classes up to man. The twelve pairs of arise fromes are seen here as in birds and mammalia, and they chiefly from the enlarged medulla oblongata.

" The following statements of Mr. Swan are full of anatomical interest.

tude In amphibia the nerves are firmer than in fishes, and acquire much magni-

not from the addition of neurilema. In the snake, those about the throat are

only tortuous, but in a considerable degree elastic, and thus allow of being 
suficiently extended in deglutition. They are large in comparison with the whole brain, but accord with the size of the oblong and spinal medulla, as in fishes. In the turtle and snake, the olfactory nerves have not distinct ganglia: after being joined by the first trunk of the fifth, they are distributed in coarse branches on the Schneiderian membrane, and appear similar, although the turtle feeds on vegetable, and the snake on animal substances; but it may be remarked, that their structure corresponds very much with that of the splanchnic plexuses, which have not ganglia intermixed with, or giving immediate origin to them. The origin of the optic nerves is from the optic lobes and thalami, and not from the optic lobes and mammillary eminences, as in fishes. In the other nerves of the orbit there is not any particular change, except that the sixth is larger, and supplies the additional muscles, which do not exist in fishes; and in the turtle the ciliary nerves proceed from a junction of branches from the third and fith nerves, but this has not the form of a ganolion. The fifth has not a very distinct smaller portion for joining the third trunk, but there is a greater resemblance to the form of the Gasserian ganglion than in fishes; the usual cutaneous branches pass through perforations in the bone to the parts beneath the horny covering in the turtle, but this disposition does not exist in the same degree in the snake, and is therefore a peculiarity for corresponding with the conformation of the parts receiving them. The par vagum and glosso-phar $\mathrm{p}^{\mathrm{n}}$. geal at their origins are not very different from the same in fishes, except that they are not so much connected with the auditory nerve; but even in the turt th and snake there are differences which may be best judged of by a reference to the plate. In the snake so many communications between the glosso-phary ${ }^{10}$. geal, par vagum, and ninth, take place before branches arc given off to supply any parts, that it is very difficult to determine with precision the destination each, for the muscles and other structures of the throat are so complicated, and at the same time so connected in function, that although the nerves be different at their origins, yet it seems they must be connected for associating the actiols of the parts receiving them. In ainphibia the par vagum appears to supp and almost entirely the heart. When the slight difference between the summit and base of the brain in the turtle and skate is considered, it cannot fail of beis the remarked that so many more nerves exist in the turtle than in the skate, as $\mathrm{ac}^{\circ}$
hard portion of the seventh, a more distinct auditory nerve, the ninth and cessory; the brain of the skate is, however, more simple in some respects, als several parts of the body are different from the turtle." 72 .

Mr. Swan states that, with respect to the sympathetic nerve, there $a^{\text {re }}$ several varieties in different genera of amphibia. In the turtle and snake, there is not a canal in which the sympathetic passes with a vertebral artery; the branch, according with the one ascending from the first thoracic $g$ ang $g^{\circ}$ lion in mammalia, passes on the outside of the spine in the turtle ${ }^{n}$ in the snake, in an incomplete canal near the connexion of the ribs with the eleven superior vertebræ. In the turtle, there is a prolongation, but ${ }^{n 0}$ cervical ganglia; it is more or less closely attached to the par vagum, bu does not exist in the snake, or, if it does, its small size prevents its being easily recognised and distinctly separated. The sympathetic does not appear to be more highly evolved than in fishes; for in the turtle, the ganglia at tached to the prolongation are very diminutive, except the first thoraci, which is broad, and has a membranous character; and in the snake, excep at its superior part, where there is one remarkable ganglion connected withe the trunk of the par vagum, and several smaller ones at the junction of the palate and nose; in the snake for some distance there are very slight plest- 
form junctions of the branches from the spinal nerves which join the proboth the ; but these plexuses are in some parts more complicated, and in of the snake and turtle exist for giving off the nerves to the viscera instead the first ase and fleshy semilunar ganglia. In the frog as in the snake, except branches cervical, no other distinct ganglia of the sympathetic exist, and the Which destined for the abdominal viscera also join a prolongation from If the splanchnic branches are derived.

the any thing definite is to be determined with respect to the functions of throumpathetic, it will be mainly effected by tracing its development spinal the ascending series of animals. A dependence of the cerebrotrace system, it will perhaps be possible, with the advance of knowledge, to the its advance from a simple spino-cerebral plexus to a system such as and plexus in man, with its special ganglia and its special apparatus of nerves The lases.

snake, last observations of $\mathrm{Mr}$. Swan relate to the spinal nerves. In the the close tells us, they are not very different from those of fishes, except in anterior aness of their origins, and the more regular communications of the leshy and posterior bundles of each nerve, and having more distinct and forminglia. In the frog there is one large nerve instead of a number plexus the axillary plexus, as in the turtle; in both however there is a posterior rembling that in the higher classes for giving off the nerves of the these, extremities, and the spinal nerves, entering it, correspond with chord, inasmuch as they have their origin from the inferior part of the spinal $\mathrm{W}_{\mathrm{e}}$ just above that from which the caudal nerves usually issue.

his cannot take our leave of $\mathrm{Mr}$. Swan without strongly recommending vere descriptis honorable and scientific labours. Those labours are of the best all ption, because they consist in the determination of particulars, on which $S_{\text {wan }}$ geralizations must be based. But we would venture to suggest to $\mathrm{Mr}$. those for the sake of the reading public, as well as for his own, to add to as particulars, generalizations and summaries as wide and comprehensive plearst knowledge will permit. His researches being thus rendered more ing will in the same ratio be more instructive.

\section{Comparative Anatomy of the Digestive Organs, Chyliferous and Sangujferous Systems.}

The two parts of Dr. Grant's Outlines before us present a very fair account $\mathrm{fr}_{\mathrm{Om}}$ apparatus of digestion in the various classes of animals. It is traced various most simple to its most complicated forms and pursued through its $\mathrm{We}_{\mathrm{e}}$ phases of development.

account shall not attempt a complete account of so extensive a subject, an jount which must necessarily comprise details unsuited for a practical some of We shall merely present in a series of slight sketches, a notice of anatomy the more striking circumstances connected with the comparative Dr. Gy of the digestive organs.

of an Grant commences their examination with some general observations "Asteresting character. We extract them.

"Ast As animal," he says, " is but a moving sac, organized to convert foreign - into its own likeness, all the complex organs of relation or af animal life serve 
but to administer to this digestive bag. The bones, connected together by their ligaments, are but the solid levers which enable the muscles to move it to and fro, and the nervous system, with its various organs of sense, serve but to direct its movements in quest of food. The unorganized food of plants is placed by nature in contact with the exterior surface of their body, and their vessels are directed thither to select and absorb it, which roots them through life to the soil where they grow; but as animals place their food within their stomach and have theil they grow ; but as animals place their food within their stomach and have and
roots directed inwards to that central reservoir, they can change their place of
move about in quest of what is most congenial to their nature. The organs the animal life relate to this difference between the two organic kingdoms, to the locomotive powers of animals for the selection of their food; but the organs of vegetative life relate merely to the assimilation of food when already within the body, and are, therefore, common to animals with plants. The alimentary surface of the plant is the exterior of its root, ramified and fixed in the soil which affords it food, so that a vegetable is like an animal with its stomach turpel inside out. As the organs of relation are those most immediately connected with the varying external circumstances of animals, they are the most variable their character and inconsistent in their existence; but those of vegetative of organic life relating to the more common and necessary functions of assimilation. are much more regular and constant in their character. No organ, indeed, is more universal or essential in animal bodies than that internal digestive cavity by which they differ so remarkably from the species of the vegetable kingdom. This internal sac is but an extension of the primitive absorbent surface of the skin, which, in animals, passes into or through the homogeneous cellular tis $s^{10}$ of the body. And, although in the simplest forms of animals, this primitive performs alone all the assimilative functions, we find it, as we ascend in th scale, giving origin to various other organic systems, to which distinct parts the the complex function of assimilation are successively entrusted. Thus the peripheral nutrition of the plant passes gradually into the central mode of inter $^{\text {. }}$ animal, and the organs of organic or vegetative life, whether they open in be nally into the digestive cavity, or on the mucous surface of the skin, may an $^{\text {a }}$ considered as originating from the exterior integument, which is itself on portion of the primitive cellular tissue of the body, modified by the stimulat of contact of the surrounding element. As the various tubulent prolongations their the alimentary canal become more and more developed and isolated from thiliar primitive source, they assume properties and functions more and more pecula and distinct, and thus form the numerous follicular and conglomerate gland apparatus, and the various vascular systems, of animals. An alimentary car is observed in every class of animals and almost in every species, and its and structure vary according to the situation of animals in the scale, or accol ing to the kind of food on which they are destined to subsist, and the extent the elaboration it requires to undergo to assimilate it to the animal's body. peculiarities presented by the digestive organs are, therefore, intimately ${ }^{c} \mathrm{al}^{\mathrm{d}}$ nected with the diversities of form manifested by the organs of animal life, ap with all the living habits and instincts of animals." 305.

\section{a. Digestive Organs of the Cyclo-neurose, or Radiated Classes.}

The lowest class of animals is termed by Dr. Grant the cyclo-neurose, ${ }^{\text {of }}$ radiated, from the anatomical disposition of its nervous system. In this class Dr. Grant examines the digestive organs as they present themselves the polygastrica - the poriphera-the polypiphera-the acalepha - tb echinoderma. We shall not follow strictly this scholastic arrangement.

A. Polygastrica. In the cyclo-neurose class, we find the simplest for ${ }^{m^{5}}$ of animal existence. In reference to the digestive apparatus, perhaps, 
polygastrica can hardly be considered to present the most simple. They

them. their name from the numerous internal digestive cavities observed in

Fr. Grant gives a general account of them in these terms :-

sacs, whe great transparency of these microscopic animals, their digestive

like, when empty, or when filled only with water as they often are, appear

or intertions of the common cellular substance of the body, or like gemmules

as aliment animalcules, and from not being easily or generally recognised

animals wery cavities, many, like Lamarck, were led to believe that these

superficial withont a mouth or any internal organs, and were nourished by

that they possorption, like marine plants. Lewenhoeck, however, observed

was seen possessed an internal cavity, and devoured each other; the same

voraciously Ellis; Spallanzani perceived them swallowing each other so

designaty that their bodies became distended with their prey; and Goetze

the smated the trichoda cimex the wolf of infusions from its rapacity among

with carm animalcules. Gleichen placed animalcules in infusions coloured

he has fane in order to discover the forms of their digestive cavities, and

internal figured many trichoda, vorticella, and other animalcules with their

Trembley sacs filled with this coloured matter; the same was done by

others.

being; but Müller supposed that they fed upon water, from their stomachs

employed frequently filled with that fluid. Ehrenberg has more extensively

cavities opaque colouring matter to detect the forms of these internal

freed and by using principally carmine, sap-green, and indigo, carefully

succeed all impurities which might prevent their being swallowed, he has

digestived better than his predecessors in unfolding the structure of the

fine partive organs of animalcules. Such coloured organic matter, diffused as

placed particles mechanically suspended in the water in which animalcules are

trans, is readily swallowed by them, and renders visible, through their

howe

distend long they remain in these coloured infusions with their stomachs

slighted with the colouring matter, it is not perceived to communicate the

possess tinge to the general cellular tissue of their body. They appear to

substances acute sense of taste in rejecting coloured metallic and other

consist chices which might prove hurtful to them, and their food appears to

or other decomp of smaller animals of the same class and of particles of mucus

In the decomposed organic matter found in the water.

alimentaryplest of the polygastrica, there is but one general orifice to the

is surroun cavities, which is placed at the anterior extremity of the body and

and tented with long vibratile cilia, which serve both as organs of motion

ment, tentacula. The several stomachs covered by the general wide integu-

orifice, open by distinct short œsophageal canals into the common buccal of dige, and there is no separate anal aperture for the excrementitious residue

the two tion. In the monas termo, continues Dr. Grant, which is only about

stomachsousandth of a line in diameter, four to six of these small round

not aphs have been observed filled with colouring matter, although they did

each appear to be half the number which might be contained in its body;

appear these stomachs, of about the six-thousandth of a line in diameter,

shaped to open, as in other anentera, by a narrow neck into a wide funnel-

attract mouth, surrounded by a single row of long vibratile cilia, which act the foating organic particles, or minuter invisible animalcules, as food. 
B. Polypiphera. The hydra, or fresh-water polype presents a very simple form of digestive apparatus. It has been described particularly, as out readers must be well aware, by Trembley. The polype exhibits a simple ${ }^{\mathrm{s}^{9 \mathrm{C}}}$ excavated in the cellular substance of the body, and destitute of all ceeca of glandular appendices, and even of a distinct anus. The parietes of this simple polype appear to possess the same properties in every part, as they continue to seize and digest food when the animal is turned inside out, and each part of the animal, when cut to pieces, is found to develop itself to a perfect polype. What was formerly the internal digestive surface is found also to become the generative, and to produce gemmules and young polypes when the animal is turned inside out. They feed chiefly on larvæ and annelides which they search for and seize by the long tentacula developed from the sides of their mouth, and they often swallow animals many times larger than their own body, by stretching their thin elastic parietes over their prey. The digested part of the food passes through the comm ${ }^{n}$ cellular tissue of their body, and through their tubular tentacula, and the residue is thrown out by the mouth.

c. Poriphera. Another very simple form of digestive apparatus is $0^{b}$ servable here. It approaches very nearly to that of plants.

The cellular tissue of their body is permeated in all directions by ramifying and anastomosing canals, which begin by minute superficial por closely distributed over every part, and terminate in larger orifices various placed according to the exterior form of the entire animal. In the min superficial absorbent pores we can generally perceive a fine transverse $g^{e^{l^{a}}}$ tinous net-work and projecting spicula, to protect these entrances from the larger animalcules and from noxious particles floating in the water. Tho internal canals, like the veinous system, leading from capillaries to trunks, are bounded internally by a more condensed or more highly organised por" tion of the general cellular substance of the body, and are incessantly traversed by streams of water, passing inwards through the minute pores, and discharged through the larger orifices or vents; but no polypi have be $e^{\text {p }}$ observed in any of those parts, nor even cilia, although from analogy we may suppose them necessary as the active agents of the currents. In this simple organization there appears to be only an increased extent given to the general cutaneous absorbent surface; there are yet no distinet $\operatorname{cec}^{\mathrm{a}}$ of stomachs for receiving and retaining the aliment that has been conveyed into the body along with the currents of water. From the incessant manner ${ }^{\text {if }}$ which these traverse the body, it would appear that all parts of the interior of these animals, like the exterior surface, of their general cellular tissue, are adapted to admit by endosmose, and to assimilate nutritious matter to the texture of their body. On watching the streams of water that issue fro $^{\mathrm{b}}$ the vents, minute flocculent particles are observed incessantly detached fro $^{\text {ll }}$ the interior, and thrown out with the currents, these appear to be fine mlt $^{\text {th }}$ cous pellicles excreted from the surface of the internal canals, as the residuld of digestion thus detached from the body. A similar mode of excretion ${ }^{\text {is }}$ often seen on the naked mucous surface of zoophytes, where thin pellicles are periodically detached from the soft exterior of the body.

So far as we have gone the digestive apparatus has been limited to this:either it has been one large pouch, with a single aperture armed with in $^{\text {- }}$ 
struments of prehension, as in the hydra-or a similar pouch with cœca ingreped from it, as in the polygastrica-or a canal, with an orifice of passing and of egress, and a current of water, carrying the nutritive matter, sented through it. A little higher and we perceive the simple idea reprethese several contrivances carried farther.

D. Acalepha. We see the central cavity provided with several canals or abertures of ingress. The resemblance to the spreading roots of trees has of rhiz for the creature which offers an apparatus of this sort, the name roophostoma, * from the immortal Cuvier. Such animals, like inverted their pos torn from their fixed attachment and floating through the sea with at the polypi extended in all directions, have numerous small pendent orifices these extremities of peduncles more or less ramified and extended, and the polypiform mouths lead by narrow canals to a central sac, from which parts of tious matter is sent by numerous radiating ramified ducts to all in diffe body. Larger and more direct openings, varying in number cavity, whimals, are also generally observed leading into this gastric compartmich is sometimes central and single, and in others is divided into B. It ments disposed around the vertical axis of the disk.

distinct is obvious that the digestive cavity would be perfected by having a should aperture for ingress, and another for egress, at its extremities. We retaininen have a digestive canal receiving the nutriment at one endresidung it for a sufficient time-and ejecting at the other end the useless this in In other words, we should have a mouth and an anus. We see canal many of the polygastrica. There is in many of them an alimentary vided, with an oral and an anal orifice, which traverses the body, and is proparietes numerous small round cœcal appendices, which open into its of stom throughout its whole course, and which appear to perform the office A machs in receiving and preparing the food.

pileus has arrangement obtains with some of the acalepha. The Beroë body, cos a straight alimentary canal passing through the long axis of its and commencing at the lower part with four thin prominent contractile tracted ighly irritable lips surrounding the wide oral aperture. The concanal, csophageal part is succeeded by a gastric expansion of this straight been containing frequently minute entomostracous crustacea which have minent allowed as food, and a narrow straight intestine terminates in a proIn the orifice at the upper part of the body.

many the Echinoderma this disposition becomes more general, and we see in con of them the evident preparation for the arrangement which becomes in the Articulata. To the latter therefore we pass.

B. Digestive Organs of THE Articulata.
ratus The Entozoa present generally the simplest form of alimentary appa-
of entot with in the articulata. In all the nematoid and more perfect forms
a distinct the alimentary canal passes simple through the body, presenting
the trunk, as in the higher articulata. The ascaris, like the other nematoid

* Pเ\{ $\alpha$ root and $\sigma \tau o \mu \alpha$ mouth. 
worms, has a single oral aperture at the anterior extremity of the body; the three marginal lobes of the mouth are provided with minute teeth and moved by distinct muscles, so that the mouth somewhat resembles that of the leecl in its masticating apparatus. The œsophagus forms a wide elongated mus" cular sac, like that seen in the halithea and some other annelides; it is $\cos ^{\circ}$ tracted at its lower part, and opens into a straight and wide intestinal can $\mathrm{n}^{2}$ with thin parietes, and where the limits of the stomach are seldom indicatel by an inferior constriction.

B. We have arrived at an intestinal tube, prolonged to a greater or a les length, and provided with an aperture at either end, adapted for the respec tive purposes of receiving or of discharging the food of the animal. The next step towards perfecting the digestive apparatus is to dilate the tube in certain situations, in order that its contents may be allowed to rest in it, and to provide it with secreting appendages which may pour upon tho $0^{50}$ contents such secretions as are adapted to act on it chemically or vitally. All this we see effected in the class of animals before us-a class which pre sents, we might say, in petto, almost all the characteristics of the ver? highest.

In the diglena lacustris, one of the rotifera, the sharp-pointed maxille and their muscular apparatus are succeeded by a lengthened and $\mathrm{narl}^{\mathrm{H}}$ œsophagus which opens into a short defined globular stomach. From differ ent parts of the stomach two large and five small elongated cœca ariset. which appear like hepatic or glandular follicles, and do not admit into thel interior the larger undivided portions of the food contained in the generat gastric cavity. From the pylorus, the intestine continues downwards nar ${ }^{20}$ and nearly straight, to terminate in the cloacal opening at the posterior end $^{\text {n }}$ of the body, close to the two fleshy peduncles.

c. We have now but to render the dilatations of the intestinal tube more definite-the secreting follicles more perfect-and to provide a trituratins? apparatus, and we have arrived at the essential items of the digestive or $\mathrm{g}^{\text {an }} \mathrm{p}^{5}$ apparatus, and we have arrived at the essential items of the digestive of in in
of the animals highest in the scale. All this we are able to distinguis
the insecta.

"The digestive organs," says Dr. Grant, " have arrived at a high degree of $^{\text {the }}$ development in insects, and already present, in an embryo-state, almost all assistant chylopoietic organs of the highest animals, as the liver, the salival glands, the pancreas, and many other parts important in the process of as $\mathrm{sin}^{\mathrm{pt}}$ lation. They vary much, however, in their form and extent of develop meliar according to the consistence and the nutritious quality of the food, the pecul to living habits of the species, and the condition of the animals with regard are their metamorphosis. The mandibulate forms of the masticating organs ${ }^{\circ 0^{\circ}}$ best adapted for comminuting hard substances, and the tubular form or $\mathrm{pr}^{\mathrm{r}}$ ire boscis for sucking food in a soft or fluid state, but even suctorial insects requ $\mathrm{r}^{\mathrm{u}}$. some form of these hard parts to pierce the surface from which they are to tain their liquid food. The mouth of insects is furnished with an upper ait lower lip (labrum and labium), a pair of strong proximate mandibles and a par of exterior maxilla which move transversely. The labium and the maxill $x^{\text {slu }}$ the port each a pair of palpi; the dense posterior part of this lower lip forms $T^{\text {the }}$ mentum, and its soft anterior portion supports the fleshy prominent tongue. masticating organs present infinite varieties of form according to the differe th $^{\text {th }}$ of food in insects, as in other classes of animals, but the same constituent pard of the mouth can be recognized in all the different forms of mandibular ${ }^{2}$ an haustellar apparatus. The same buccal organs form broad, short, and stro 
cutting instruments, which move transversely, in those insects which subsist on traction, and a long, slender, tubular apparatus, capable of extension and refrom th, in those which suck fluid or soft substances. These parts often change food in one form to the other in the same insect, while it changes its kind of the la the progress of its metamorphosis; and where the food is the same in condition and imago, the masticating organs preserve the same form in these two mixed with of the insect. The food reduced by the mandibles and maxilla and by a with the secretion of one or more pairs of salivary glands, is transmitted esopharynx of variable length, to the œsophagus and alimentary canal. The of crop us commences by a narrow canal which generally forms an enlargement lowed. $p$ at its lower part, for receiving and collecting the food when first swalglandular enlargement of the œsophagus is often covered with minute short strong follicles which open into its interior. Below the crop is a small but $\mathrm{r}_{\mathrm{u}}$ lon mitular gizzard, with thick parietes, and provided internally with numerating gitudinal rows of hard sharp conical horny teeth. This muscular trituits aid stomach is most developed where the hardness of the food most requires $f_{00 d}$ is as in most of the orthopterous and coleopterous insects; but where the ceptible liquid, as in most of the sucking hemiptera, the gizzard is scarcely perin insects The largest, the most constant, and the most important gastric cavity generally, is the long, wide and highly glandular chylific stomach which extends stomach from the gizzard to the insertion of the hepatic ducts. The chylific licles, whis, for the most part, amply furnished with considerable glandular folinto its which are developed from its whole parietes, and open by separate orifices by numerior. This cavity is frequently of great length, and partially divided anterior transverse constrictions, it is then most wide and glandular at its tion. $i_{s}$ most intestine, from the termination of the chylific stomach to the anus, dilatation vable in its length and capacity, and in the number and extent of its mentary. Like the masticating organs, the gastric cavities and the whole aliWhich thenal have their forms regulated and impressed by the kind of food sume. mach in the voracious and inactive condition of the developing larva, the stoWhich it ten found of enormous capacity compared with the diminutive size to

Winged is reduced in the more parsimonious and active state of the mature The imago.

externalimentary canal of insects presents a distinct internal mucous lining, an can be peritoneal coat, and muscular fibres, both transverse and longitudinal, a smoothily perceived in its parietes. The interior of the mucous coat presents nor valvu surface, as in most of the lower invertebrata, having neither plicæ, a loose forms cellular or follicular enveloping tissue. The exterior peritoneal coat of trachestinct thin mesentery, which is covered with the minute ramifications terior of and which connects the convolutions of the intestine with the inair-vesselse abdominal segments. The ramifications of these white opaque arger ins on the mesentery are seen in the common blue fly, and in most of the ${ }^{r} \mathrm{esel}_{\mathrm{s}}$. Thects, without the aid of a lens, and appear like the branches of blooddomen The peristaltic motion of the intestine is obvious on opening the abthe in of the living insect; and in the short trunks of many of these animals, Weasures several times the length of the whole body." 349.

D. We have arrived at what we may consider a pretty perfect formula for one for apparatus. That consists of several subordinate apparatus-of or oo trituration-for dilation or insalivation-for transmission (a pharynx canal, withus) - for chymification and chylification, a stomach and intestinal and, with its secreting appendages, pancreas and liver or their analoguesally, for defæcation. It is not consistent with our present object to 
enter fully on the examination of each part of this complicated and perfect apparatus. But we may observe that, in the animals which have it, it is modified according to the circumstances which affect them, and on those modifications we shall lightly touch.

\section{c. Modifications of the Digestive Organs in the Higher Anima ${ }^{\text {s. }}$}

A. The circumstance which above all others modifies the digestive appat ratus, is the animal or vegetable nature of the food. We see this as strongly marked in the articulata as in the vertebrata, and hence the great division of animals into carnivorous and granivorous.

In the carnivorous, the digestive tube is shorter-the glandular organ frequently less perfect-the triturating infinitely less so-the intestin dilatations less marked and less disposed to affect the form of cœca.

In the granivora, the converse of all this is seen, and the triturating ap paratus especially, perfected.

We may compare, for example, the carnivorous insect-the cicindela campestris, with a herbivorous-the common coleopterous cockchaffer.

In the former, the digestive canal passes nearly straight through the body. The œsophagus, commencing narrow as usual from the posterio opening of the head, dilates below into a wide crop, presenting severt longitudinal rows of very minute follicles. The crop is succeeded by a shor muscular gizzard, and this by a capacious chylific stomach, covered with numerous glandular follicles, and tapering downwards to its pyloric tremity, where it is perforated on each side by two simple convoluted hepatic vessels. From the chylific stomach the intestine continues downwards ver? vessels. From the chylific stomach the intestine continues downwards fore
narrow, and nearly straight, to a short dilated colon, which contracts befol
it terminates in the cloaca.

In the cockchaffer, which feeds on the leaves and shoots of our garden plants, the whole digestive apparatus is long, complicated, and capacions The œsophagus passes out narrow from the head, and dilates below into short conical crop, which is succeeded by a very minute gizzard, and a $100 \%$ convoluted chylific stomach, The anterior portion of this lengthened $g \cdot a a^{\circ}$ dular stomach is wide and sacculated by numerous transverse stricture and terminates insensibly in a narrow convoluted pyloric part, which dilate into a small round vesicle at the lower end, where it receives the opening of the hepatic vessels. The two hepatic vessels on each side are here, accordance with the coarse nature of the vegetable food, very long, wide and convoluted, and have their secreting surface greatly extended by th development of innumerable small lateral follicles, which give them a pin nated form throughout the greater part of their course; thus presentin ${ }^{\text {th }}$ most complicated condition of the liver met with in insects. The lower portion of the intestinal canal has also its capacity increased by distinct dilatations on the parts analogous to the colon and the rectum.

B. The varieties exhibited by one of the dilatations of the digestive tube' B. The varieties exhibited by one of the dilatations of the digestive
the stomach, display the modifications dependent on circumstances
striking manner.

In a pure carnivorous mammal it may be a simple globular sac. Frot that simple form we may trace it to the less carnivorous tribes, to th 
quadrumana and man, in whom it bas become transversely elongated with cardiac fundus or cæcum. In many of the rodentia, the thin membranous constriac portion forms a considerable cæcum, and is partially separated by a developmen from the more muscular pyloric half of the cavity. The great in the beavt of the gastric glands around the cardiac orifice of the stomach which beaver and the wombat, is required by the coarse vegetable food on glandular subsist, and points out an analogy between this part and the several infundibulum at the cardiac orifice of the gizzard in birds. In the pal phytophagous mammalia, belonging to different orders, as among or exchydermata, masupialia, edentata, and even quadrumana, internal folds tent, and cceca divide the cavity of the stomach to a greater or less exformed from the epidermic lining extending over the cardiac sacs thus cetacea we observe a gradual transition to the complex stomachs of the structurea and ruminantia, where the several compartments have different But it and functions.

velopment in the ruminantia that the stomach has attained its acmé of desist upent. As Dr. Prout has observed no cookery can enable man to subof apon the grasses. Yet they furnish the food of a most important class rectly lis, and these being chiefly the food of man hinself, he thus indithe grasses upon the grasses. The means by which the ruminantia convert "

"The ruminating quadrupeds have the masticating and salivary organs most tions, the œsophagus long and narrow, four gastric cavities with distinct funccacum coli. intestine and colon long, capacious and distinct, and an enormous lama coli. The œsophagus, as seen in the annexed figure of the stomach of the placed Peru, enters directly into the first large cavity or paunch (ingluvies), the cheek the left side, analogous to the crop of birds, and serving the office of divided -pouches of other quadrupeds. This capacious cavity is partially subvilli, ed large internal folds, and is lined with closs, small but lengthened distinctly with a thick epidermis. The same epidermic covering is continued placed over the second and third cavities. The second stomach or reticulum its mucoure anteriorly and to the right of the former, is much smaller, and has This ucous lining elevated into reticulate folds forming polygonal shallow cells. muscular also communicates with the œsophagus, and presents two thick Which a valvular folds across the opening of communication, by the closing of The canal is formed which leads to the third cavity of the stomach.

$q u a n t i t y n c h$ receives the crude-unmasticated vegetable food collected in large generally while the animal is erect and grazing, and the process of rumination rest. In commences when this cavity is filled, and the animal is reclining at softened rumination, small portions of the unmasticated food, moistened and as a bolus, the paunch, pass into the second cavity to be sent by its contraction, being thor, upwards through the muscular œsophagus to the mouth. After soft thoroughly masticated and salivated in the mouth, the bolus returns, as a findsulp, by the œesophagus; and, its stimulating quality being now altered, it shortened two valvular folds at the lower end of the osophagus closed, and into the by contraction, and is directed by the short canal they thus form, foliated third, and thence into the fourth cavity of the stomach. The third or gated stomach (omasum) is generally the shortest and smallest, though elonnumerous narrow in the camelus and auchenia, and is provided internally with gins dire longitudinal, alternately small and large folds, having their free martheir rected to the centre of the cavity. The second and third cavities have those linin membrane covered with small villi and distinct epithelium, like $\mathrm{N}_{0}$. LVI. 
abomasum, which is next in capacity to the paunch, lined with a soft highly vascular mucous coat, provided internally with large longitudinal folds, and apparently destitute of epidermic lining. The structure and form, and $\mathrm{sect}^{\mathrm{e}}$ tions of this fourth cavity, placed on the right side of the others, render it of proper digestive stomach, and the most analogous to the single digestive $\mathrm{saC}^{\mathrm{C}}$ carnivorous and higher quadrupeds." 411.

The means by which the camel is enabled to carry a supply of water suff ficient for its consumption in the desert have been fully described by ${ }^{\text {it }}$ Everard Home. The following brief notice of the apparatus by $\mathrm{Dr}$. Gra will be sufficient to give our readers an idea of it.

In the camels, dromedaries and lamas, numerous rows of large, quadral gular, deep water-cells are developed on the parietes of the second stom $\mathrm{mach}^{\mathrm{c}}$, and on the parts of the paunch next to that eavity. These cells are sut rounded by muscular fibres which, by their contraction, are capable of es cluding the food from the water-cavities; and by the gradual opening of the cells, the water is allowed to mix in successive small portions with digesting aliment. These animals are thus enabled to convey and econ mise a large supply of pure water, received at long intervals in the ar plains they inhabit. The second stomach is more appropriated to the retent tion of water than the large paunch, and receives it directly from the mouth unmixed with the food, pouring over to the cells of the first stomach a qua tity of the fluid when its own are filled.

It is curious to observe the manner in which Nature not unfrequents accommodates herself to circumstances, and makes the same organs with slight alteration perform almost different uffices. The transformations the embryo and fotus, the metamorphoses of insects, will at once presel themselves to the mind of the anatomist, and he finds in the ruminantia instance of the same description. Their complicated stomachs are calct lated and intended for the digestion of most indigestible substances. the ruminating animal is a calf before it is a bull, and, when a calf, lives ip its mother's milk, a highly nutritious liquid. Observe the modification the action of the stomachs at this period.

"The fourth stomach of the ruminantia is the first developed, the largest, alone employed for digestion, during the earlier periods of existence and dut the lactation. The milk, in suckling, passes down through the œesophagus to closed valvular folds, which check its entrance into the first or second sto liate and convey it along the canal which they form, directly to the third or fol cavity. The third stomach not having been yet distended with solid food $5^{5} \mathrm{r}^{\circ}$ to separate from each other its numerous contiguous laminæ, it merely for the a tube through which the milk passes into the fourth stomach; and thus $90^{\circ}$ nutritious fluid of the parent is conveyed directly into the proper digestive ${ }_{201}$ ? mach of the suckling ruminant, without being accumulated or retarded in of the previous cavities." 412 .

c. The triturating apparatus presents in the different classes of animals remarkable variety. In the highest class we see it principally at the ver? entrance of the alimentary canal, and the moveable jaw, with its tell adapted for cutting and for grinding, is of course familiar to us all. But many animals the triturating implements are not at the entrance of the many animals the triturating implements are not at the entrance of
digestive tube, but at the stomachic dilatation. We see this not unfreque
in the articulata. 
The small mouth, says Dr. Grant, of the halither aculeata, furnished with two conical tentacula or antennæ, opens into a short membranous esophagus, which terminates in a large muscular stomach with thick firm cavity is and a strong coriaceous lining. The entrance of this muscular analogis furnished with four sharp, triangular, converging, horny teeth and gous to those of the gastric toothed cavity of insects and crustacea; lumbricus is also analogous to the muscular stomach of the arenicola, nematoid, and many other annelides, and to that of the ascuris and other matoid entozoa.

The wide crustacea, the gastric teeth are seen in a state of high development. of wide buccal cavity of the decapods, surrounded with complicated organs into a and of mastication, opens by a very short and narrow œsophagus calcareopacious stomach, provided internally with several pairs of solid As their teeth, and occupying the anterior part of the cephalo-thorax. saljivary watery element almost bathes this gastric cavity, they require no shed lik glands to soften their moist food. The gastric teeth, colored and and are the exterior shell, are symmetrically disposed near the pylorus, muscles supported by thin elastic calcareous laminæ, to which powerful grindes are attached, and which cause the teeth to meet with precision in Aning the contents of the stomach.

in the form of gastric triturating apparatus is the gizzard. Existing stome articulata, it attains its maximum in birds. It is a small muscular of food, having a horny epidermic lining, and, to assist in the comminution of the the bird swallows stones, which, acted on by the muscular parietes conte gizzard, bruise and grind the grain. Oddly enough, Spallanzani $D_{r}$. Granted that this was from stupidity. The stupidity was Spallanzani's. - Grant's description of a gizzard is as follows :-

"These muscular parietes of the gizzard form two stron

one antese muscular parietes of the gizzard form two strong digastric muscles,

$\mathrm{Ou}_{8}$ anterior, the other posterior, with white shining tendons, in most gallinace-

rapacious granivorous birds, and in many aquatic and other species. In most

thin aus and carnivorous birds, the parietes of all the three gastric cavities are

constrictighly extensible, and form almost one continuous stomach, with slight

these bitions between its parts. The thin membranous gizzard however of

to tho birds presents a distinct anterior and posterior central tendon, analogous

fasciculi of the two ordinary digastric muscles, and from which the muscular

the cavity more or less developed in different species, radiate to the margins of

parietes

coriace, as in the gallinaceous birds, its internal epidermic lining forms a thick

them to dense coat, to protect the soft parts from laceration, and to enable

teeth to act with effect upon their heterogenous contents. From the want of

pebbles the mouth to act upon their hard food, these granivorous birds convey

the gastric other dense substances into their gizzard, to reduce their food, like

but in thic teeth of crustacea, insects, many gasteropods, and other invertebrata;

swall the carnivorous birds, with a thin membranous gizzard, no pebbles are changes in or required, the activity of the secretions affecting all the necessary

moves in the conditions of the food, aided by the high temperature, and the

of the pyloric gizzard, it forms a sac open only above, and is not provided with the and widehincter muscle, so common in other vertebrated classes. This free cavities, pyloric orifice allows the food, partially digested in the three gastric

small suad reduced by the muscular action of the gizzard, to pass out, in successive portions, to the commencement of the duodenum. The small 
internal capacity of this strong grinding organ, which is chiefly filled with peb bles, necessitates the development of other gastric cavities between it and the mouth, to receive a sufficient quantity of coarse vegetable food for the mainte nance of these large and heavy birds." 403.

The powers of the gizzard were put to the test by Felix Plater. He gare a hen a Louis d'or-a royal meal. In a short time, we forget just now how long, it lost sixteen grains of its weight. An onyx lost in the gizzard a fourth of its weight.

Carnivorous birds, who have a very imperfect gizzard, may be brought to live on grain, when a powerful gizzard becomes developed. On the ther $^{\text {the }}$ to live on grain, when a powerful gizzard becomes developed. On the ght to
hand, granivorous birds, who swallow stones, cease to do so if brought
feed on animal matters.

D. The varieties of beak in birds are highly interesting. They represent the teeth in being organs of offence or defence, the lips, \&c. in being orgat of prehension. Dr. Grant's remarks on this head are succinct, but nol uninteresting.

The jaws, he says, have their alveolar margins covered, like those of chelonia, with borny plates, which vary in their forms, according to the kind of food, like the teeth of mammalia. The nearest approach to the teeth of quadrupeds is seen in the thin horny laminæ disposed along the sides of the bills in the mallard, and some other aquatic birds; and in the earliest condition of the birds the laminæ begin by a series of small detached tubercles, provided each with its pulp, its nerve, and its vessels, like the horny maxillary plates of the whale, and the more solid calcareous teet of other vertebrated animals. The broad depressed bills of ducks, gesel swans, and many other aquatic birds, with dentated edges, and soft sensitiv lips, are well adapted for obtaining worms or other small objects under water or in mud, and they commonly present a well-marked dental distr bution of the alveolar nerves and blood-vessels, as well as a high develop' ment of the second and third branches of the trigeminal nerves. The spatulate jaws of the spoon-bills are adapted for quick lateral motion in th waters, and for extracting minute animals from the moist banks of labe and rivers. The submaxillary pouch of the pelican serves as a net for seizing fishes; the straight sharp bills of cranes and storks dart with per cision through the water upon their moving prey, and the long compresset bills of cormorants, gulls, albatroses, and many predaceous aquatic bi ${ }^{d{ }^{d}}$ terminate above in a sharp inverted hook, to seize firmly the smooth $\mathrm{scl}^{\mathrm{a}} \mathrm{l}$ bodies of fishes. The broad bills, with cutting edges, of the struthe $0^{\omega^{5}}$ birds, are adapted to prune the leaves and shoots of plants, and the $100_{0}^{\circ}$ narrow bills of woodpeckers to be inserted into small crevices to seiv minute insects ; and most of the insectivorous order of birds have a simil structure on a smaller scale. The long tubular beak of the humming bir is suited for insertion into the corolla of flowers. In the grosbers crossbills, the sparrows and buntings, and all the granivorous order, ${ }^{\text {n }}$ in the larger gallinaceous birds, the bills form stronger and shorter $\mathrm{cos}^{\mathrm{p} \mathrm{p}^{\mathrm{s}}}$ broader at the base, to break down and remove the hard coverings of grain In the climbing frugivorous cockatoos, parrots, and maccaws, the broad an powerful bills serve as prehensile organs, and to break the hard shell. coverings of seeds. The bills of eagles and vultures, hawks and ow $/ 5, a^{a p}$ other rapacious birds, are strong, short, compressed, arched, curved at 
point, dense in their texture, and with sharp cutting edges, to seize, and parts and cut the flesh of living prey. So that the forms of these external digestion pond with and indicate the structure of the internal organs of class.

E. The length to which this article has already run precludes the idea of our proceeding much farther. We are tempted to allude to one, and but one, the subject. Every one is aware how feeble, in point of chemical action, becomary secretion is. Yet in certain circumstances, this same secretion that pos a most formidable instrument of death in the jaws of the creature gland liesses it. The parotid of the rattle-snake is the poison gland. That

is embehind and below the orbit on each side, contained in a wide cavity, perforated by a slip of the temporal muscle, and sends its long duct to the Here base of the poison fang.

fascinat then, we pause. In succeeding numbers we shall resume the the devating subject of Comparative Anatomy, and present a few sketches of perforelopment of the various apparatus by which the vital functions are We in the ascending scale of animals.

and recommend the Outlines of Dr. Grant to the attention of our readers, lightful partarly of the younger portion of them. They will find much deits low and some useful knowledge in our author's pages. The work, from of all. price, may be in the hands of most men-should be in the hands

patical Observations on Nervous and Sympathetic Palpitation of the Heart, particularly as distinGuished from Palpitation the Result of Organic DisEASe; to Which are prefixed some General Remarks ON THE USE OF THE STEThoscope, AND EMPloyment of Percussion in Diagnosis of Diseasfes of the Heart and LNGs. By John Calthrop Williams, M.D. Physician to the Nottingham Dispensary, \&c. \&c. London, 1836.

$A_{M_{1} N_{G}}$ the arguments adduced in favor of Provincial Medical Schools, we regat remember having seen any notice taken of their beneficial effects as masters the teachers themselves. Urgently called upon to make themselves think of the subjects which they are to discuss, they are led to study, and Way upon them much more intently than they would otherwise do. In this Who number of labourers in the field of science is increased, and men lessly might, but for the application of such a stimulus, have plodded thoughtobser on along the beaten road of practice, become careful explorers and These, and consequently safe guides for the conducting of others.

as is remarks are elicited by the fact that the volume before us consists,

stance stated in the Preface, of observations which originally formed the subof part of a course of lectures on the principles and practice of 